\title{
From Yellow to Orange: Using Cost-Benefit ANALYSIS TO INFORM LOCAL HOMELAND SECURITY DeCISION-MAKING
}

\section{By Charlotte Kirschner}

Abstract: After the September 11, 2001 terrorist attacks, officials at all levels of government were faced with difficult policy decisions concerning public security. Many policymakers were asked to make security decisions hased on limited information about the nature or credihility of potential threats. Using San Francisco as a case study this article applies the technique of cost-henefit analysis to a hypothetical decision by that city to raise its threat level - in Homeland Security terms, to go from "yellow to orange." The article demonstrates how a policymaker might conduct a cost-henefit analysis when the benefits and costs of a decision are contingent on the unknown prohability of an event occurring. This analysis highlights the importance of information-sharing between levels of government and demonstrates the affect of a policy decision on the probability of terrorist attack. The lessons learned provide important insights for the many government officials currently facing risk-dependent policy decisions.

In the weeks following September 11, 2001, federal government officials began developing strategies to prevent future terrorist attacks in American cities. Policymakers quickly realized that effective prevention would rest largely on the federal government's ability to communicate recommendations to heighten vigilance to local decision-makers. The United States (U.S.) government responded by creating the Homeland Security Advisory System (HSAS), which enables federal officials to raise or lower the national threat level as new intelligence becomes available. However, while raising the national threat level initiates a series of security responses throughout the federal bureaucracy, there are no guidelines for city Charlotte Kirschner is a doctoral student at The George Washington University School of Public Policy and Public Administration. During her tenure at GWU she has focused on homeland security and terrorism. Her research includes studies on the costs and financing of homeland security policies. Before coming to GWU, Ms. Kirschner worked for the Administrative Offices of the Pennsylvania Supreme Court where she conducted macro-level policy research and managed the caseload statistics system. She received her Master of Social Service from Bryn Mawr College and her Bachelor of Arts in Psychology and Women's Studies from Syracuse University. and state governments to follow. Instead, responses are left to the discretion of local dẹcision-makers, who are provided with limited information regarding the "real risk" faced by their cities.

Given the public sensitivity toward security concerns and the potential loss of life associated with the risk of a terrorist attack, local government officials often find themselves in the difficult position of trying to make important decisions about safety with inadequate information. Although local government officials are typically willing to spend resources on added precautions, spending is difficult to justify when threats turn out to be minimal or even false. As former Secretary of Homeland Security Tom Ridge has noted, a local government official's decision to raise the threat level can be controversial. In an Associated Press article by Iara J. Jordan on May 10, 2005, Ridge stated "[r]aising the terror alert level generally costs state and local emergency responders millions of dollars in overtime salaries, causes widespread travel delays and takes a hit on the public's psyche."

Using San Francisco as a case study, this article applies the technique of cost-benefit analysis to a hypothetical decision by that city to raise its threat level - in Homeland Security terms, to go from "yellow to orange." The results of this analysis provide important insights for local gevernment officials who 
are asked to make public welfare decisions during highly uncertain times. The article shows how a policymaker might conduct a cost-benefit analysis when the benefits and costs are contingent on the unknown probability of an event occurring. While this analysis demonstrates specifically how a local official's decision to go from "yellow to orange" can impact the likelihood of a terrorist attack on a city, the technique can be applied to a wide array of policy contexts in which officials are faced with difficult disaster mitigation decisions.

\section{History and Purpose of the}

\section{Homeland Security Advisory}

\section{System}

Immediately after the September $11^{\text {th }}$ attacks, the federal government issued a series of broad warnings recommending that both citizens and local governments maintain a state of high vigilance regarding security threats. Critics believed these general warnings confused local authorities and alarmed the public (Sostek 2003). In response, on March 11, 2002, President George W. Bush issued Homeland Security Presidential Directive 3 (HSPD-3), which established the Homeland Security Advisory System (HSAS). According to HSPD-3, the purpose of the advisory system is "to provide a comprehensive and effective means to disseminate information regarding the risk of terrorist acts to Federal, State, and local authorities and to the American people" (U.S. President 2002, 394). The system can either be used to alert the entire nation or, when the intelligence permits, to highlight threats against specific states, cities, or industries.

Modeled after the Department of Defense's Threatcon system, the HSAS has five levels, each of which describes a different threat condition and provides a list of recommended protective measures that should be implemented at each alert level (see Appendix, Table A-1). With the exception of military facilities, all federal agencies are required to disband any preexisting threat advisory systems utilized by the agency and to comply with the directives in HSPD-3, along with the subsequent variations in alert levels. Although state and local governments and private industry are not required by law to comply with the HSAS, the Department of Homeland Security (DHS) recommends that they do so. ${ }^{1}$

When determining the threat level, federal officials consider the available intelligence information while concentrating on the following criteria: the credibility of the information; the level of corroboration; the specificity and urgency of the threat; and the gravity of the potential consequences of the threat (Reese 2005). When the HSAS was initiated, the national threat level was determined to be at yellow, or elevated, alert. Since its inception, the level has never been lower than yellow, but it has been raised to orange, or high alert, seven times. ${ }^{2}$ The first five times the alert was raised to orange were general alerts for the entire nation and were relatively short in duration. The sixth time the system was activated the nation stayed at yellow while financial sectors in New York City, areas of northern New Jersey, and Washington, D.C. were raised to orange. This alert lasted more than four times longer than the average length of the earlier alerts. The system was activated again on July 7, 2005 for a period of 36 days after the bombings of the London Underground. DHS raised the alert level to orange only for mass transit systems and the alert was lowered once mass transit had an opportunity to put long-term security measures in place. ${ }^{3}$ While DHS has not created a regional alert system to notify emergency responders about specific threats, as recommended by the Gilmore Commission, these recent cases indicate a trend of limiting the scope of the HSAS alerts to situations where intelligence can direct the alert to specific jurisdictions or industries.

\section{Reactions to Raising the}

\section{Terror Alert}

As there are no specific requirements for state and local governments to fulfill when the national alert level is raised, developing and enacting a local response is left to the discretion of individual jurisdictions. Under the assumption that the alert level is raised for valid reasons, most states and local jurisdictions will decide to raise their alert levels as well. Raising the alert level generally means that cities will increase security at strategic targets while attempting to limit the burden 
placed on the public. Typical measures that cities and states take include activating surveillance cameras, increasing port security patrols, placing first responders on alert, increasing patrols by mass transit law enforcement officers and increasing surveillance of sensitive locations, such as courthouses, bridges, and shopping centers (Reese 2005). All of these measures impose significant costs on state and local governments.

Some government officials are willing to bear the costs of the added security that accompany taising the alert level. Dennis Beyer, chair of the technical advisory group for Tulsa, Oklahoma's homeland security task force reported, "[a]s a local government, we cannot afford not to prepare for the low-probability, highconsequence events ... There are too many lives at stake" (Sostek 2003, 22). However, because of these costs, other cities choose not to participate in the orange alerts unless they are provided with specific threat information. When the Federal government raised the alert in February 2003, the Governor of Hawaii chose to maintain a blue or "guarded" level. The Governor of Arizona announced that he would consider a similar policy for his state and base a decision to raise the threat level on whether or not there is a specific threat to Arizona (Gilmore 2003). For four of the five national alerts, city officials in Charlotte, North Carolina opted to remain at what they describe as "dark yellow," believing that a temporary security increase would not provide a significant improvement in security and might waste city resources. Instead, they focused on improving general preparedness by creating programs to increase communications among first responders (Sostek 2003). Other cities have scaled back their response to a national threat level change. In Washington, D.C., for example, police officers worked their regular eighthour shifts throughout one orange alert rather than the twelve-hour shifts they had worked during previous alerts (Sostek 2003).

One issue that complicates the decision to raise the local security threat level is that city and state officials struggle to determine the "real risk" to their populations when the national threat level is raised without receiving specific information about the nature or credibility of the threat. According to a Government Accountability Office (GAO) report completed after the first three times the alert level was raised, officials from state and local government agencies indicated that more specific information from DHS regarding the nature of the threat would have been helpful in determining the additional actions they should take at the local level (GAO 2004). Without specific information from DHS regarding the nature of the threat, assessing the risk to any particular city is complicated by the fact that every city has critical infrastructure to protect (such as a water supply and government offices). As a result, elected officials are often willing to spend local resources on added precautions for smaller cities with relatively low risk of attack. Some city officials believe conveying an image of preparedness and security will further lower their risk of attack as potential terrorists opt for easier targets. Therefore, small cities often spend scarce local resources on protective measures when the alert is raised in an effort to deter attacks from occurting in their city, even if it is not considered a cost-effective decision (Sostek 2003).

\section{San Francisco at Risk}

According to a RAND Corporation model developed in 2003, San Francisco is among the top six American cities that could be likely targets for the next terrorist attack. The model calculates terrorism tisk by examining the potential value of property damage to a city, the target's symbolic value to the U.S., how easy the target is to attack, and how likely it is to be destroyed if it is attacked. If the model is accurate, San Francisco is the third most likely target, only preceded by New York and Chicago, with Washington, D.C., Seattle, and Los Angeles completing the list. RAND notes that the model ranks economic damage higher than the iconic value of landmarks, which explains why Washington, D.C. ranks fourth. After the top six cities, there is no significant difference in the relative risk posed to other American cities (UCLA International Institute 2003).

The DHS believes San Francisco exhibits both asset-based and geographically-based risk (DHS 2005). Asset-based risk focuses on the assets within a jurisdiction that might be susceptible to a terrorist attack. For example, nuclear power plants, theme parks, mass transit systems, and national monuments and icons are some of the assets that increase a jurisdiction's risk of terrorist attack. Geographically-based risk ascribes tisk 
to jurisdictions based on unique characteristics that are not attributable to a specific asset. For example, jutisdictions with military bases or high population density are examples of places with high geographically-based risk.

\section{Cost-Benefit Analysis: AN}

\section{Appropriate ToOL}

As city and state officials struggle with the decision to raise local security alert levels following a notification of potential threat from DHS, they are implicitly weighing the benefits of preventing a potential attack against the costs of raising the alert level. With fixed financial resources, officials are striving for an efficient allocation of funds, making cost-benefit analysis (CBA) an appropriate tool for aiding this policy decision. In Risk and Reason, Cass Sunstein suggests that cost-benefit analysis is

"a simple pragmatic tool, designed to promote a better
appreciation of the consequences of regulation. A
government that uses cost-benefit anabysis is certainly
entitled to consider who is belped and who is
burt...Properyy understood, cost-benefit analysis is no
theology. It is instead an effort to assist both
government and citizens, in bope of ensuring that
risk regulation will actually promote its purposes."
-(Sunstein 2002, 5)

As a tool to aid decision-makers, cost-benefit analysis considers how the policy being analyzed affects economic welfare. While economic welfare is not the only criterion that should be taken into account when making policy decisions, it is important for the efficient use of scarce resources. Additional methods could be used in conjunction with CBA to evaluate other criteria or socictal values such as the potential effect of policy decisions on civil liberties or perceptions of personal safety.

Although critics of CBA remain, Sunstein reports that the U.S. government is reaching the end of the initial debate on whether or not to use CBA to make regulatory decisions. He reports that an informal bipartisan agreement has been reached in favor of using cost-benefit analysis. The consensus recognizes that governments should: 1) assess the magnitude of any problem that it is trying to solve; 2) analyze tradeoffs by exploring the costs of regulation; and 3) use inexpensive and effective tools to conduct this analysis (Sunstein 2002). While Sunstein recognizes that the first two tasks should be done in quantitative terms whencver possible, he determines that a cost-benefit analysis "entails a full accounting of the consequences of risk reduction, in both quantitative and qualitative terms" (Sunstein 2002, 106). With the additional information from CBA, government officials can make more informed decisions.

A cost-benefit analysis requires several steps. First, the analyst must determine the alternatives - in this case, to raise the local HSAS alert level from yellow to orange or to remain at yellow. Next, policymakers must determine which parties have standing, or whose benefits and costs they will consider in the analysis. This study considers the impact on city governments and taxpayers in San Francisco and Oakland, as well as on those individuals who live in, work in, or travel between these cities. The purpose in choosing this population is to include anyone who may become a victim of a terrorist attack on San Francisco or Oakland. This analysis assumes that taxpayers in San Francisco and Oakland would be willing to pay to prevent a terrorist attack on all people, not simply taxpaying citizens. ${ }^{4}$

Third, the analyst must determine the costs and benefits of each policy altemative. Impacts of the policy must be catalogued, quantified whenever possible, and assigned a monetary value over the life of the project. Impacts that cannot be quantified and/or monetized should be discussed in qualitative terms so decisionmakers are aware of the additional cost or benefits even if a specific dollar value cannot be attached to the impact.

Fourth, benefits and costs that will occur in the future need to be discounted to obtain present values of the impacts. Given the relatively short period of time that the national alert level has gone to orange, no impacts will occur in the distant future and discounting is not necessary. However, the uncertainty of a terrorist attack occurring during an orange alert requires the completion of an expected value analysis before determining the net present value. ${ }^{5}$ The net present value (NPV) of each alternative can then be determined by subtracting the costs from the benefits.

Some uncertainty always exists in the process of quantifying and monetizing the impacts of the policy 
alternatives. In this analysis, there is uncertainty in the probability of a terrorist attack as well as some uncertainty in the estimates used to measure the impacts of raising the terror alert level to orange. To account for the considerable amount of uncertainty in a CBA, the analyst should perform a sensitivity analysis to examine the effects of varying the values of different impacts on the NPV. According to Boardman et al., sensitivity analysis is "a way of investigating the robustness of net benefit estimates to different resolutions to uncertainty" (Boardman et al. 2001, 156).

Finally, the policymaker makes a recommendation based on the NPV and the sensitivity analysis. The general tule is to recommend the policy alternative with the highest NPV. For this analysis, the policymaker should raise the alert level if the NPV is positive.

\section{IDENTIFICATION AND MEASUREMENT OF Costs AND Benefits}

While many costs and benefits of raising the terror alert level from yellow to orange are identifiable, not all impacts are measurable. Table 1 provides a summary of the impacts of raising the alert level and notes which costs and benefits will be measured in this analysis. Assuming the national HSAS level has been raised to orange, the costs and benefits of raising the terror alert level from yellow/elevated to orange/high for the city of San Francisco will be compared to the counterfactual policy of leaving the alert level at yellow.

\section{Measured Costs}

\section{Increased city security presence}

When the national HSAS level is raised from yellow to orange, city governments that decide to raise their own alert levels typically do so by increasing the city's security presence. For example, to ensure adequate coverage some cities initiate a twelve-hour workday for police officers and other security personnel, tather than eight-hour shifts. This security upgrade generally requires significant spending for overtime pay. According to a recent study, during the May 20 through May 30, 2003 orange alert period, the San Francisco Police Department reportedly double-checked critical locations during each shift and closely monitored public events with large crowds (Reese 2005). Another CNN.com article by Ensor et al. on May 22, 2003 noted that portions of the Golden Gate Bridge and surrounding bike trails were closed as a result of an alert level change, with additional security dispatched to patrol the entrances.

Since government officials seldom reveal all specific measures taken when the alert level is raised, determining the precise costs associated with these measures is difficult. Therefore, an estimate of these costs was obtained from a 2003 U.S. Conference of Mayors survey on the subject. The U.S. Conference of

Table 1: Measured Costs and Benefits

\begin{tabular}{|c|c|c|}
\hline & Costs & Benefits \\
\hline Measured & $\begin{array}{l}\text { Increased City Security Presence } \\
\text { Police Presence Increased } \\
\text { Screening of People and Vehicles } \\
\text { Increased Wait Times At Airports }\end{array}$ & $\begin{array}{l}\text { Costs Avoided by Preventing Attack } \\
\text { Lives Saved } \\
\text { Injuries Prevented } \\
\text { Property Destruction Avoided } \\
\text { Emergency Response Costs Saved } \\
\text { Tax Revenues Lost } \\
\text { Emotional Stress Avoided } \\
\text { Reduction in Crime }\end{array}$ \\
\hline $\begin{array}{c}\text { Not } \\
\text { Measured }\end{array}$ & $\begin{array}{l}\text { Increased Wait Times on Highways } \\
\text { Increased Security for Private Industry } \\
\text { Decreased Tourism } \\
\text { Crisis Fatigue }\end{array}$ & Capturing Terrorists \\
\hline
\end{tabular}


Mayurs survey of nearly 150 cities described the costs related to the high threat alert. 'The survey reveals that during a state of heightened alert, cities nationwide are collectively spending nearly $\$ 70$ million per week in additional homeland security costs." San Francisco reported spending $\$ 2.6$ million per week. These costs are in addition to the existing homeland security expenditures that cities were already spending to maintain general security measures (U.S. Conference of Mayors 20(13).

The survey's respondents were asked to report only direct costs of raising the alert and not to report indirect costs such as the effects of reassigning police officers from their usual responsibilities to guarding a public building. The reported costs also do not include the costs of equipment and training that the citys first responders need to ensure that they are prepared to react in a time of crisis (U.S. Conference of Mayors 2003). Therefore, the cost figures might underestimate the total cost because they exclude the indirect costs borne by society. However, these costs might also be overestimated because they include extra security measures due to the war in Iraq. Although the figures are not exact, for the purpose of this analysis, San Francisco's estimate of $\$ 2.6$ million per week will be used as a close estimate of the costs of raising the threat alert level to orange.

The U.S. Conference of Maỹors report did not include information on Oakland's costs during an orange alert. Thereforc, to determine the increased security costs of raising the alert in Oakland, the San Francisco cost figure was scaled down ptoportionally based on the ratio of the two cities' police departments. According to the Bureau of Justice Statistics for 1999, Oakland had approximately one-third the number of full-time sworn officers as San Francisco (Bureau of Justice Statistics 2003). Oakland's cost of raising the alert level to orange for a period of one week was therefore determined to be $\$ 760,000$.

Of the seven times the HSAS was raised to orange, the median number of days the threat lasted was 20 days (see Appendix, "Table A-2 for the number of days each orange alerr lasted). Table A-3 (see Appendix) shows the calculations necessary to transform these reported weekly costs to a cost of the average orange alert for the two cities, the result of which is $\$ 9.6$ million per instance of raising the alert (in 2003 dollars).

\section{Increased wait times at airports}

When the national terror alert is raised from yellow to orange, new security checkpoints emerge at national landmarks, entrances of private businesses, and airports. When the HSAS was raised to orange in December 2003, airport officials advised the public $t o$ plan to spend an additional half an hour to an hour at the airport because of added security procedures. Passengers were told to expect delays both at security checkperints inside airports and due to random vehicle searches cutside terminals (Avation Week 20013). Not all passengets will experience an additional half an hour delay at the airport because of the increased security measures. However, whether it proves necessary or not, passengers arriving a half an hour earlier for their flights to accommodate increased security measures still spend that time waiting at the airport.

According to the Airports Council International (ACI), San Francisco International Airport (SFO) served over 32 million passengets in 2004 (ACI 2005). This figure was divided by two to determine the number of passengers departing from $\mathrm{SFO}$, as they are the most likely to be affected by additional security problems. This figure might overestimate the number of passengers affected by security because the total passenger figure also includes passengers with a layover at SFO; however, the sensitivity analysis that follows will provide an opportunity to address this possible overestimation. Data were not available to differentiate between business travelers and individuals traveling for pleasure, so the U.S. Department of Transportation (DO'T) average hourly value of travel time savings for all air travel purposes was used to calculate the additional social costs (DOT 2003). Table A-4 (sce Appendix) details the calculations used to arrive at the additional $\$ 13.5$ million of costs for the average orange alert.

\section{Measured Benefits}

\section{Costs avoided by preventing a terrorist attack}

Even when the intelligence is detailed enough to warn a specific city, local officials will not likely know for what type of attack to prepare. Although the 9/11 atrack was execured with "conventional" high explosives, the next attack could be biological, chemical, or nuclear. For this case study, an assumption was made that the next attack will be of similar magnitude to the 
September $11^{\text {th }}$ attacks in New York City, the effects of which will be scaled down proportionally for San Francisco and Oakland.

GAO reviewed eight studies from seven different organizations on the economic impact of the September $11^{\text {th }}$ attacks on New York City. It determined that the study conducted by the New York City Partnership and Chamber of Commerce provided the most comprehensive estimate of the economic impacts (GAO 2002). ${ }^{8}$ The New York City Partnership estimated that the economic impact of the attack was likely to reach a total of $\$ 83$ billion (2001). The direct and indirect costs included in this estimate are shown in Table 2.

The New York City Partnership and Chamber of Commerce reviewed their initial analysis in the months after the attacks as some costs became more evident. They determined that two factors night have contributed to an overestimation of total costs. First, the clean up of ground zero was occurring at faster rates and lower costs than anticipated. Second, the original report overestimated loss of life by over 2,000 lives. incorrect death projections. Economists use several different methods to approximate the value of a human life, but the following two are most common. The first method uses current wage rates to discount potential future earnings and determine the value of lost productivity. This method results in using a different value per life for high wage earners (typically men in the prime of age) and low wage earners (often women, children, and minorities). The second method uses a risk compensation approach to determine the amount people are 'willing to pay to reduce the risk of death. This method uses the same value of life for all people, which typically results in a higher total cost for the loss of life. The Partnership valued human life based on lost productivity, rather than the value of a statistical life." Therefore, the $\$ 83$ billion figure was used in this analysis because GAO considered it the most comprehensive estimate, even with the overestimates for clean up costs and number of lives lost. The New York Partnership value also lies within the range of estimates from the other studies (GAO 2002).

In order to estimate the economic impact of an attack on San Francisco, it was necessary to scale down

Table 2: Direct and Indirect Costs Measured in Estimate of 9/11 Impact

\begin{tabular}{lc}
\hline \multicolumn{1}{c}{ Direct Costs } & \multicolumn{1}{c}{ Indirect Costs } \\
\hline Hutman lives & Lost Employee Income and Business Profits \\
Property loss & $*$ Days businesses closed or services cut back \\
* Buildings & because of office infrastructure damage or \\
* Technology and Fixtures & destruction \\
* Subway Stations & * Other firms that depend on those that are closed or \\
* Phone and Power Utilities & cut back \\
Response to the Emergency & Reduced Tax Revenues \\
* Emergency Management (including loss of & Delays for Travelers and Commuters \\
equipment) & \\
* Debris Removal & \\
$*$ Building Stabilization & \\
Health Effects, Injuries, and Emotional Distress & \\
Temporary Living Assistance & \\
\hline
\end{tabular}
Source: New York City Partnership and Chamber of Commerce (2001).

The methodology used to determine the value of lost lives may have countered some of the cost overestimation caused by the quicker clean-up and the calculated impact of the September $11^{\text {th }}$ attacks by accounting for the population difference between New York City and San Francisco and Oakland. To 
find a per capita cost of the New York City attacks, the economic impact was divided by the 2001 population of New York City. A total of the population for New York's five boroughs was used since the entire area was affected by the attacks. This per capita cost of September $11^{\text {th }}$ was then multiplied by the combined 2004 population of San Francisco and Oakland to obtain the estimated value of benefits, which totals over $\$ 12.2$ billion, from preventing a similar attack in San Francisco or Oakland. Table A-5 (see Appendix) shows these calculations.

\section{Reduction in crime}

The changes in terror alert levels result in more police officers on the street to portray a visible security presence. This increase in security might not only deter potential terrotists, it also deters other types of criminals. A 2005 study found a 15 percent reduction in street crimes, mostly auto-theft and burglary, during high-alert days in the District of Columbia (D.C.) (Klick and Tabarrok 2005). D.C., however, has a few unique characteristics that suggest this finding might be an overestimate when trying to generalize to other populations. For example, the majority of the crime reduction found in this study occurred in the police district that includes the National Mall. Despite controlling for the effects of tourism, police presence on the National Mall increases more than in other areas of the city during orange alerts, in part because of the federal law enforcement presence in addition to city police. The closed circuit television system on the Mall is also activated when the city is at orange alert.

Theoretically, a situation could occur in other cities in which no significant reduction of crime happens. For example, if a city decided to save the costs of police overtime, it might choose to relocate police officers already on duty to protect specific areas, rather than extending shifts and increasing the police presence across the city. If this situation occurred, there would be a transfer in crime location instead of a reduction of crime. For these reasons, a mean of 7.5 petcent crime reduction will be used to estimate this impact. The sensitivity analysis will evaluate a range of burglary and motor vehicle theft rate reductions from zero to 15 percent.

According to the Uniform Ctime Report, 22,854 burglaries and motor vehicle thefts occurred in San Francisco and Oakland during 2003 (FBI 2004). This aggregate figure translates to an average of 63 burglaries or motor vehicle thefts per day. Again using the median terror alert of 20 days, a 7.5 percent reduction in these street crimes during the average orange alert would result in the prevention of 92 crimes. Some estimates suggest that the shadow price of an individual burglary is $\$ 16,200$ (in 1999 dollars) (Boardman, et al. 2001). ${ }^{10}$ After accounting for inflation, preventing 92 burglaries or motor vehicle thefts will result in $\$ 1,638,412$ in benefits for the cities. Table A-6 (see Appendix) displays the calculations necessary to obtain this estimate.

\section{Unmeasured Costs and Benefits}

In most analyses, some costs and benefits are not measurable. Costs and benefits might not be measurable because the data are not available or because the item is not quantifiable. In this analysis, at least four areas of costs are not measured: increased wait times on highways, increased security for private industry, decreased tourism, and crisis fatigue. Likewise, the additional benefit of potentially capturing terrorists is not measured. When costs or benefits cannot be quantified or monetized, the decision-maker can still consider the effects in a qualitative manner and estimate their impact on the results. If the impact of the unmeasured costs and benefits is considered large enough to shift the sign of the net present value, the analyst may wish to determine proxy values for the unmeasured impacts.

\section{Determining Net Present}

\section{VALUE}

As previously discussed, both the benefits and costs of increasing the HSAS level from yellow to otange occur over a relatively short period of time. Therefore, discounting the impacts to adjust for the time value of money is unnecessary. However, an expected value analysis is required because of the uncertainty that the policy change will prevent a terrorist attack. The set of contingencies possible when considering raising the HSAS alert level are displayed in Table 3, along with an indication of when costs and benefits would be realized. To calculate the NPV, the analyst must 
determine the probability of a terrorist attack. Once this probability is estimated, an expected value analysis can be used to calculate the NPV. of terrorists to adapt makes determining the probability of their actions difficult.

Posner suggests "inverse cost-benefit analysis" as an alternative to determining the probability of catastrophic events. This procedure determines the probability of a terrorist attack $(\mathrm{P})$ by dividing the

Table 3: Possible Contingencies - When Benefits and Costs are Realized

\begin{tabular}{|c|c|c|c|c|}
\hline & \multicolumn{3}{|c|}{ Does terrorist attack occur? } \\
\hline & & \multicolumn{2}{|c|}{ No } & \multirow[b]{3}{*}{ Yes } \\
\hline & & \multicolumn{2}{|c|}{ Was an Actual Attack Preempted? } & \\
\hline & & No & Yes & \\
\hline \multirow{2}{*}{$\begin{array}{l}\text { Is terror } \\
\text { alert level } \\
\text { raised? }\end{array}$} & No & $\begin{array}{l}\text { Status quo - no } \\
\text { additional costs and no } \\
\text { additional benefits }\end{array}$ & $\begin{array}{l}\text { No costs of raising the } \\
\text { alert level, benefits are } \\
\text { realized but attributable } \\
\text { to other policies }\end{array}$ & $\begin{array}{l}\text { No costs of raising threat } \\
\text { level, and benefits ate not } \\
\text { realized }\end{array}$ \\
\hline & Yes & $\begin{array}{l}\text { Cost of raising alert level } \\
\text { incurred but the only } \\
\text { benefits realized are from } \\
\text { reduction in crime }\end{array}$ & $\begin{array}{l}\text { Costs of raising alert level } \\
\text { incurred and bencfits are } \\
\text { realized }\end{array}$ & $\begin{array}{l}\text { Cost of raising the threat } \\
\text { level compounded by } \\
\text { benefits that are not } \\
\text { realized }\end{array}$ \\
\hline
\end{tabular}

\section{Determining the Probability of a Terrorist}

\section{Attack: Inverse Cost-Benefit Analysis}

Whereas the probability of a naturally occurring catastrophe, such as a hurricane or tsunami, can be estimated using scientific knowledge and historical trends, the probability of a terrorist attack cannot be estimated. Richard Posner explains "[i]t is not only that terrorists are secretive as to plans and capabilities, but also that they - or at least the ones that have vague and encompassing aims - have such a wide range of potential means and targets to choose among, and if suicidal, cannot be deterred" (Posner 2004, 174). The human element of terrorist activity makes deterrence extremely difficult. While hurricanes might veer from the anticipated path because of changing ocean currents, it is nearly impossible for a hurricane to change its course as a result of human countermeasures. Terrorists, however, are largely driven by human rather than physical phenomena; they react to human countermeasures and adapt appropriately. This ability amount the government is spending to prevent a particular type of attack $(C)$ by the anticipated socinl losses of the terrorist attack actually occurring (L). This formula results in an implied or subjective probability of the terrorist attack. Therefore, if $\mathrm{C}$ and $\mathrm{L}$ can be estimated, $P$ can be calculated using the formula for expected cost $(C=P L)$. For example, if $\$ 1$ billion is spent to avert an attack that will create $\$ 100$ billion in losses, the subjective probability of such an attack occurring is $\mathrm{P}=\mathrm{C} / \mathrm{L}=\$ 1$ billion $/ \$ 100$ billion $=.01$ or one percent (Posner 2004).

This method has several weaknesses. First, using government budgets to determine probabilities relies on the subjective opinions of policymakers. Behavioral psychological theories suggest that in the wake of the September $11^{\text {th }}$ attacks, individuals are prone to overestimate the likelihood of another attack and decision-makers are likely to divert resources towards preventing an attack even if the magnitude of risk does not warrant the actions (Sunstein 2003). Therefore, analysts should use government budgets with caution when estimating the probability of an attack, as this technique could result in an overestimation. Another 
concern with using this method of arriving at the subjective probability is that it assumes one dollar spent on prevention equals one dollar of reduced risk. However, without information on the marginal costs and marginal benefits of terrorism prevention, using total costs and total anticipated losses is the best proxy measure available. Although the inverse cost-benefit analysis method is imperfect, it provides a more realistic method for estimating the probability of an attack than other methods, which are open to manipulation by the terrorists themselves or are the result of inaccurate assessments of risk by the insurance industry. ${ }^{11}$

\section{Implementing the Inverse Cost-Benefit}

\section{Analysis Method}

In the specific case of San Francisco, since the cost of a successful terrorist attack is $\$ 12.2$ billion and the total estimated monetary cost of going to an elevated alert level is $\$ 23.1$ million, the resulting subjective probability of an attack is .0019 . The implication of this estimate is that, in the case of San Francisco, going to an orange alert level would be a socially efficient use of scarce resources if this action reduced the probability of a terrorist attack to approximately 2 in 1000. Interestingly, this estimate is of the same order of magnitude as the implied probability that would make current expenditures devoted to reducing the probability of a 9/11-type attack in New York City just equal to expected benefits. ${ }^{12}$

\section{Calculating the Net Present Value}

NPV is calculated by subtracting the present value of the costs from the present value of the benefits of implementing the policy - in this case raising the HSAS level from yellow to orange in San Francisco. As previously mentioned, no discounting is necessary, but the expected value analysis does complicate this procedure. The following formula is used to calculate the NPV:

$$
\mathrm{NPV}=(\mathrm{p}(\mathrm{A})+\mathrm{B})-\mathrm{C}
$$

In this formula, $\mathrm{p}$ is the probability of an attack occurting, $A$ is the cost avoided if a terrorist attack is prevented, $B$ is the value of other benefits that are not contingent on preventing a terrorist attack, and $C$ is the value of the costs associated with raising the alert. Calculating the expected values of the costs or the reduction of crime is unnecessary because these impacts are not contingent on the probability of a terrorist attack; if the alert level is raised, those impacts will be realized. Using the data discussed above and displayed in Table A-7 in the Appendix, the NPV was determined to be approximately $\$ 1.7$ million. This result indicates that if the estimates are correct, local policymakers should raise the alert level because the benefits outweigh the costs by $\$ 1.7$ million. However, before making a final decision, policymakers should conduct a sensitivity analysis.

\section{Sensitivity ANALYsis}

Since the NPV is based on estimates of variables, running a sensitivity analysis of the vatiables in which there is the greatest amount of uncertainty provides useful insights about the reliability of the NPV. Typically, a sensitivity analysis attempts to control for uncertainty by using the most plausible estimates of unknown quantities, known as a base case. If the sign of the NPV does not change when a range of reasonable assumptions is considered for uncertain values, the analysis is considered robust and greater confidence can be held in the results (Boardman et al. 2001).

A Monte Carlo Sensitivity Analysis was completed with the assistance of Crystal Ball, a software program designed for completing this type of analysis. Boardman et al. 2001 describe a Monte Carlo analysis as "playing games of chance many times to elicit a distribution of outcomes" (Boardman et al. 2001, 173). When conducting a Monte Carlo analysis, one must first determine the most likely probability distributions for the variables in the analysis. Next, a random draw from the distribution of each variable is taken to arrive at a set of values for computing net benefits. Finally, the random draw is repeated many times to generate a large number of estimated net benefits. The larger the number of random draws, the more likely the result will be an accurate representation of the actual net benefits (Boardman et al. 2001). 


\section{Assumptions of the Sensitivity}

\section{Analysis}

The Monte Carlo analysis tequires the identification of the uncertain variables. In this analysis, those variables are the net costs of waiting time at airports, the net benefits of preventing a terrorist attack, and the net benefits from the reduction in crime. ${ }^{13}$ While the probability of a tertorist attack is also uncertain, this vatiable will be held constant during the Monte Carlo analysis. Instead, this uncertainty was controlled for by tunning the Monte Carlo analysis with four fixed probabilities of a terrorist attack occurtring. This analysis assesses the costs and benefits of raising the alert level when the probability of an attack is known. The four probabilities were selected around the "break even" case of .0019 , which was determined by the inverse cost benefit analysis above. Table A-8 in the Appendix summarizes the variable assumptions in the analysis.

\section{Value of waiting time at airports}

The distribution of this variable is assumed to be triangular. A triangular probability distribution is a faitly simple distribution, which takes into account the most likely value of the distribution, along with a maximum and minimum value. Although the analysis assumes that most individuals will heed directives to arrive at the airport a half an hour earlier than they would have had HSAS been at yellow, some individuals will probably ignore this advice and will not have any additional waiting time. However, other individuals will end up waiting longer than a half an hour. When lines at security checkpoints get long, airport personnel typically begin removing people with imminent departures from the line. Given that most airlines terminate the boarding of aircraft ten minutes before flight time, the analysis assumes that the maximum amount of additional time an individual could be waiting at the airport because of an orange alert is forty minutes. This slightly positively skewed distribution is displayed in Figure 1 (see Appendix).

\section{Value of preventing a tertorist attack}

For the purpose of the sensitivity analysis, the distribution of this variable was assumed to be triangular, with a minimum value of $\$ 7.9$ billion and a maximum value of $\$ 15.4$ billion, centered around the baseline value used in the analysis of $\$ 12.2$ billion. The GAO review of reports analyzing the impact of September $11^{\text {th }}$ on New York City included impacts as low as $\$ 54$ billion and as high as $\$ 105$ billion (GAO 2002). The same per capita scaling applied to the base case was applied to these minimum and maximum values to establish the range of possible benefits from preventing an attack in San Ftancisco. The triangular distribution was chosen because it provides a continuous distribution and is an approximation of a random variable with an unknown distribution. These assumptions lead to a distribution that is slightly positively skewed. Figure 1 also displays the distribution with these assumptions (see Appendix).

\section{Reduction in ctime}

The analysis assumes that this variable has a uniform distribution. A uniform probability distribution is a simple distribution that only requires a minimum and maximum value and assumes that all values in between the two values are just as likely to occur. This distribution was chosen because there is no theoretical reason to believe that any one value has a higher probability of being correct than any other value. As noted above, information on the actual reduction of crime during orange alerts is limited. The 15 percent reduction established in the one available study is assumed to be an upper bound of this impact. The analysis also assumes that a reduction in crime might not occur. Figure 1 in the Appendix shows this distribution, as well.

\section{Results of Sensitivity Analysis}

Two thousand cases were run for each of the four different probability levels: $p=.001, p=.0015$, $p=.002$, and $p=.003$. Figure 2 displays histograms of the realized benefits (see Appendix). The analysis of 2000 cases was conducted to achieve at least a 95 percent confidence level in the results. The analysis shows that if the probability of thwarting a terrorist attack was 1 in 1000, the mean simulated net benefit is -\$8.1 million with a six percent chance that the simulated benefits are positive. In other words, when the probability of a successful terrorist attack was 1 in 1000 , rather than .0019 as assumed in the base case, the costs of raising the alert level would outweigh the 
benefits by $\$ 8.1$ million. Since the analysis shows that the lower probability level would only yield a net increase in benefits six petcent of the time, raising the alert level would not be recommended. Similatly, if the probability of preventing an attack was 1.5 in 1000 , the mean simulated net benefit is $-\$ 2.1$ million. Once the probability of a terrorist attack increases to 2 in 1000 (the approximation of the base case), the simulated mean net benefits increases to a positive $\$ 3.8$ million and the chance that the net benefits would be positive reaches 73.6 percent. If the probability of a successful terrorist attack increases to 3 in 1000, the mean net benefit equals $\$ 15.7$ million and there is a 99 percent chance that the net benefits will be positive. Table A-9 in the Appendix displays these results.

\section{Conclusion}

A city's decision to increase its HSAS alert level from yellow to orange requires the weighing of costs and benefits. For the city, costs include the price of increasing a security presence in areas of critical locations. The San Francisco and Oakland city governments' costs for increasing the alert level were determined to be approximately $\$ 9.6$ million for the average alert time period of 20 days. The cost of increased waiting time at airports was estimated as $\$ 13.5$ million. Other social costs that were not measured include private industry costs for securing their facilities, increased wait time at highway checkpoints, and any possible decrease in tourism.

The primary benefit from a city's decision to raise the alert level is the possibility of preventing a terrorist attack. Based on a scaled down simulation of the economic impacts of September $11^{\text {th }}$ on New York City, the potential benefits to San Francisco and Oakland from preventing this type of attack would be approximately $\$ 12.2$ billion. However, because the likelihood of a terrorist attack is uncertain, an inverse cost-benefit analysis was used to determine when expected benefits would just equal the expected costs of the elevated alert level. This inverse cost-benefit analysis allows you to determine a "break even" case when the probability of a terrorist attack is .0019. The analysis estimated that the cities would also obtain an additional $\$ 1.7$ million in benefits from the additional security measures.
Four Monte Carlo sensitivity analyses were run on this base case varying the probability of a terrorist attack from 1 in 1000 to 3 in 1000. The analysis determined that positive net benefits would result from raising the alert level 73.6 percent of the time when the probability of a tertorist attack is 2 in 1000 . Given the uncertainties involved in obtaining these estimates, a reasonable inference from the analysis is that spending the resources associated with going to an elevated alert level in San Francisco represents a reasonably socially efficient use of scarce tesources especially if local decision-makers choose to err on the side of caution.

For San Francisco and other cities, this analysis is helpful in two important and distinct ways. First, it provides an example to practitioners of how to conduct a cost-benefit analysis when the actual benefits and costs are contingent on the chance of an event occurring and the probability of occurrence is unknown. While cost-benefit analysis should not be the sole decision tool for policymakers, this analysis demonstrates how economic efficiency can be a contributing factor in decision-making during times of uncertainty. The federal government has not exempted homeland security policies from regulatory impact analysis and this type of analysis will likely be conducted at the federal, state, and local level with increasing frequency. For example, some federal grant programs, such as the Hazard Mitigation Grant Program administered by the Federal Emergency Management Administration (FEMA), require evidence of cost-effectiveness when providing grant funds (FEMA 2004).

Second, this analysis demonstrates the importance of knowing the probability of a terrorist attack and the likelihood of reducing that probability with any given policy. In this example, the reduction of the probability of a terrorist attack from 3 in 1000 to 2 in 1000 could save San Francisco $\$ 11.8$ million. Therefore, city officials should continue to press the federal government for specific information regarding the credibility of the threats. Also, smaller cities, which are typically considered at less of a risk for a terrorist attack, might want to consider finding ways of preparing for a terrorist attack, tather than continuing to raise and lower the city's threat levels.

Since Hurricane Katrina, federal, state, and local policymakers have begun to shift their focus from 
terrorism preparedness to an all-hazards approach for the next disaster. Whether preparing for terrorism, hurricanes, or avian flu, this cost-benefit analysis framework can help policymakers prepare for the varied risks our cities face. As government officials learn more about these threats, cost-benefit analysis will become an increasingly useful tool, helping decision-makers cope with the complexities of allocating scarce resources in times of great uncertainty.

\section{Notes}

${ }^{1}$ Specifically, HSPD-3 states "[at] each Threat Condition, Federal departments and agencies would implement a corresponding set of "Protective Measures" to further reduce vulnerability or increase response capability during a period of heightened alert. ... The Homeland Security Advisory System shall be binding on the executive branch and suggested, although voluntary, to other levels of government and the private sector"' (U.S. President 2002, 394).

${ }^{2}$ Table A-2 in the appendix provides a list of dates and reasons the HSAS was raised from yellow to orange, along with the total and median number of days the system was at orange.

${ }^{3}$ The author reported this observation as a result of periodic monitoring of The Department of Homeland Security website: http://www.dhs.gov/ dhspublic/display?theme $=29$. Note, the website has been modified since these observations were made.

${ }^{4}$ In order to determine the impact of the City of San Francisco's decision to respond to the rise in the national HSAS level from yellow to orange, Oakland, California was included in the analysis. The two cities are connected by the San Francisco-Oakland Bay Bridge and many citizens work or travel to the other city. For simplification of analysis, an assumption was made that if San Francisco opts to activate a response, Oakland will do so as well.

${ }^{5}$ Expected value analysis allows for the analyst to account for the probability of an event occurring in the analysis by multiplying the value of the cost or benefit times the probability of the event occurring. So for example, if you earned a dollat if the flip of a coin resulted in a heads, then the expected value of the flip would be fifty cents $(\$ 1.00)$ (probability $=.5)=$ $\$ .50$.

6 The U.S. Conference of Mayors figures were collected as the nation was going to wat in Iraq. Therefore these figures are attributed to the additional security costs due to the raised terror alert level and the wat in Iraq.

7 All airports fall under the jurisdiction of the Transportation Security Administration and are therefore required to initiate additional security procedures when the national HSAS is raised. Therefore, the actual costs of additional security personnel are not included as the federal government provides these services and does not have standing in this analysis. While the federal government does not have standing, San Francisco travelers do. Therefore, assuming that San Francisco would only raise its alert level in conjunction with the federal government raising the national level, the waiting time of those departing from SFO were considered.

8 In making this determination, GAO compared each study's methods and assumptions to standard economic analysis, specifically examining the extent to which each study accounted for the following, among other things: 1) major categories of short-run and longrun losses; 2) included only the cost required to rebuild or restore property to pre-attack levels; 3) avoided double counting losses; and 4) included a baseline to control for the economic slowdown underway before the attack (GAO 2002).

2 The New York City Partnership study valued life at $\$ 2$ million ( $\$ 2$ million $* 5000$ lives $=\$ 10$ billion). In a recent study Viscusi and Aldy determined that "the value of a statistical life for prime-aged workers has a median value of about $\$ 7$ million in the United States" (New York City Partnership and Chamber of Commerce 2003, 68). Using this figure, the estimated cost of lives lost during the attack in New York City should be closer to $\$ 19.5$ billion ( $\$ 7$ million * approx. 2,750 lives lost). Therefore, the net impact of these estimations could be an underestimate.

${ }^{10}$ Shadow pricing is a generally accepted technique to determine benefits and costs when the social value of 
a good cannot be determined accurately from observed prices, or when the observed prices do not exist.

${ }^{11}$ Other methods of estimating the probability of a terrorist attack include using information markets or the insurance industry for estimating risk. See Posner (2004) for further information on these methods and their weaknesses.

${ }^{12}$ Specifically, it has been estimated that a repeat of the Sept. $11^{\text {th }}$ attack in New York City would cost $\$ 86.2$ billion, and estimated government expenditures needed to avert a repeat disaster have been estimated to be $\$ 137.6$ million. The reduction in the probability of attack that equates cost with benefit in this case is .0016 .

${ }^{13}$ Although there is undoubtedly some uncertainty in the value of costs borne by San Francisco and Oakland to provide an increased security presence, no information on the range of that value or indications about the shape of the distribution were available. Therefore, this figure was not varied in the sensitivity analysis.

\section{ReFerEnCES}

Airports Council International (ACI). 2005. 2004 North America Traffic Report: Total Passengers. Washington, D.C.: ACI. http://www.aci-na.org/ (accessed August 9, 2005).

Aviation Week. 2003. Security boosted in orange alert. Airports. New York, NY: McGraw-Hill Companies, December 23.

Boardman, A. E., D. H. Greenberg, A. R. Vining, and D. L. Weimer. 2001. Cost-benefit analysis: Concepts and practice. 2d ed. Upper Saddle River, NJ: Prentice Hall.

Bureau of Justice Statistics. 2003. Law Enforcement Management and Administrative Statistics Database. http://bjsdata.ojp.usdoj.gov/ dataonline (August 13, 2003).

Ensor, D., J. King, S. MacVicar, B. Start, and T. Frieden. 2003. Threat level to remain at 'orange' through holiday: Security stepped up around nation amid warnings. CNN.com, May 22.
Gilmore, Governor James. 2003. Forging America's new normalcy: Securing our homeland, preserving our liberty. Fifth Annual Report to the Ptesident and the Congress of the Advisory Panel to Assess Domestic Response Capabilities for Terrorism Involving Weapons of Mass Destruction.

Jordan, L.J. 2005. Ridge: Homeland cautious on alert level. Associated Press, May 10.

Klick, J., and A. Tabarrok, 2005. Using terror alext levels to estimate the effect of police on crime. Journal of Law and Economics XLVIII: 267-279.

New York City Partnership and Chamber of Commerce. 2001. Working together to accelerate New York's recovery: Economic impact analysis of the September $11^{\text {th }}$ attack on New York City. New York: New York City Partnership and Chamber of Commerce. http:/ /www.nycp.org/reports / ImpactStudy.pdf (accessed May 12, 2005).

Posner, R. A. 2004. Catastropbe: Risk and response. New York: Oxford University Press.

Reese, S. 2005. Homeland Security Advisory System: Possible issues for congressional oversight. Washington, D.C.: Congressional Research Service.

Sostek, A. 2003. Orange crush: The confusion and cost of complying with national terror alerts are driving cities to question the whole system. Governing Magazine, August.

Sunstein, C. 2002. Risk and reason: Safety, law, and the environment. New York: Cambridge University Press.

2003. Terrorism and probability neglect. Journal of Risk and Uncertainty 26: 121-136.

UCLA International Institute. 2003. RAND tries to model risks of terrorist attacks. Los Angeles, CA: UCLA International Institute. http:// www.international.ucla.edu/ (accessed May 13, 2005).

United States Department of Mayors. 2003. Survey on cities' direct homeland security cost increases related to war/ bigh alert. Washington, D.C.: United States Conference of Mayors. http://usmayors.org/ uscm/news/press_releases/documents/ survey_032703.pdf (accessed April 14, 2005). 
United States Department of Homeland Security (DHS). 2005. Discussion of the FY 2006 Risk Metbodology and the Urban Areas Security Initiative. Washington, D.C.: DHS.

United States Department of 'Transportation (DOT). 2003. Revised departmental guidance: Vahation of travel time in economic analysis. Washington, D.C.: DOT.

United States Federal Bureau of Investigation (FBI). 2004. Uniform crime report: 2003. Washington, D.C: FBI.

United States Federal Emergency Management Agency (FEMA). 2004. HMGP: Frequently asked questions. Hazard Mitigation Grant Program. http:// www.fema.gov/fima/hmgp/faqs.shtm (accessed April 2, 2006).

United States Government Accountability Office (GAO). 2002. Impact of terrorist attacks on the world trade center. GAO-02-700R. Washington, D.C.

2004. Homeland Security Advisory System: Preliminary observations regarding threat level increases from yellow to orange. GAO-04-453R. Washington, D.C.

United States President. 2002. Directive, Directive on the Homeland Security Advisory System, Homeland Security Presidential Directive 3. Weekly Compilation of Presidential Documents 38, no. 11:394-7 (March 18). 


\section{APPENDIX}

\begin{tabular}{|c|c|c|}
\hline \multicolumn{3}{|c|}{ Table A-1: Homeland Security Advisory System Threat Levels } \\
\hline Threat Level & $\begin{array}{c}\text { Risk of Terrorist } \\
\text { Atack }\end{array}$ & Protective Measures \\
\hline $\begin{array}{l}\text { Green } \\
\text { Low }\end{array}$ & Low & $\begin{array}{l}\text { * Refine preplanned protective measures } \\
\text { * Ensure personnel trained on HSAS and preplanned protective } \\
\text { measures } \\
\text { * Institutionalize a process for assuring all facilities are assessed for } \\
\text { vulnerabilities and measures are taken to mitigate these } \\
\text { vulnerabilities }\end{array}$ \\
\hline $\begin{array}{c}\text { Blue } \\
\text { Guarded }\end{array}$ & General & $\begin{array}{l}\text { * Check emergency response communications } \\
* \text { Review and update emergency response procedures } \\
\text { * Provide information to public that would strengthen its ability to } \\
\text { react to an attack }\end{array}$ \\
\hline $\begin{array}{l}\text { Yellow } \\
\text { Elevated }\end{array}$ & Significant & $\begin{array}{l}\text { * Increase surveillance of critical locations } \\
\text { * Coordinate emergency plans with other federal, state and local } \\
\text { facilities } \\
\text { * Assess the threat and refine protective measures as necessary } \\
\text { * Implement contingency and emergency response plans }\end{array}$ \\
\hline Orange High & High & $\begin{array}{l}\text { * Coordinate security efforts with federal, state and local law } \\
\text { enforcement agencies } \\
\text { * Take additional protective measures at public events or possibly } \\
\text { consider changing venues or canceling } \\
\text { * Prepare to execute contingency procedures, such as moving to an } \\
\text { alternate site or dispersing workforce } \\
\text { * Restrict facility access to essential personnel only }\end{array}$ \\
\hline $\begin{array}{c}\text { Red } \\
\text { Severe }\end{array}$ & Severe & $\begin{array}{l}\text { * Increase or redirect personnel to address critical emergency needs } \\
\text { * Assign emergency response personnel and mobilize specially } \\
\text { trained teams } \\
\text { * Monitor, redirect, or constrain transportation systems } \\
\text { * Close public and government facilities }\end{array}$ \\
\hline
\end{tabular}

Source: Reese, S. 2005. Homeland Security Advisory System: Possible issues for congressional oversight. 


\begin{tabular}{|c|c|c|}
\hline \multicolumn{3}{|r|}{ Table A-2: HSAS Threat Level Changes } \\
\hline Dates & Days At Orange & Reasons for Change \\
\hline $\begin{array}{l}09 / 11 / 2002 \\
09 / 24 / 2002\end{array}$ & 13 & $\begin{array}{l}\text { Terrorist threat information based on debriefings of a senior al Qaeda } \\
\text { operative }\end{array}$ \\
\hline $\begin{array}{l}02 / 07 / 2003 \\
02 / 27 / 2003\end{array}$ & 20 & $\begin{array}{l}\text { Intelligence reports suggest al Qaeda attacks on apartment buildings, hotels } \\
\text { \& other soft targets }\end{array}$ \\
\hline $\begin{array}{l}03 / 17 / 2003- \\
04 / 11 / 2003\end{array}$ & 25 & $\begin{array}{l}\text { Intelligence reports indicate al Qaeda would probably attempt to launch } \\
\text { attacks against U.S. interests to defend Muslims \& Iraqi people }\end{array}$ \\
\hline $\begin{array}{l}05 / 20 / 2003 \\
05 / 30 / 2003\end{array}$ & 10 & $\begin{array}{l}\text { After bombings in Saudi Arabia \& Morocco, U.S. intelligence believes al } \\
\text { Qåeda beginning operational phase worldwide, including attacks on the } \\
\text { United States }\end{array}$ \\
\hline $\begin{array}{l}12 / 21 / 2003 \\
01 / 09 / 2004\end{array}$ & 19 & Increased terrorist communications indicating attacks \\
\hline $\begin{array}{l}08 / 01 / 2004 \\
11 / 10 / 2004\end{array}$ & 98 & $\begin{array}{l}\text { Intelligence indicates al Qaeda planning attacks on financial institutions in } \\
N Y, D C \text {, and NJ, since before } 9 / 11\end{array}$ \\
\hline $\begin{array}{l}07 / 07 / 2005 \\
08 / 12 / 2005\end{array}$ & 36 & $\begin{array}{l}\text { After bombings in London, the Department of Homeland Security taises the } \\
\text { alert for mass transit systems including regional and inter-city passenger rail, } \\
\text { subways and metropolitan bus systems in fear of a duplicate attack }\end{array}$ \\
\hline & & an Number of Days at Orange Alert $=20$ \\
\hline
\end{tabular}

Source: Reese, S. (2005). Homeland Security Advisory System: Possible issues for congressional oversight. 
Table A-3: Transformation of Cost Figures

\begin{tabular}{llr}
\hline San Francisco's Reported Cost per Week & a & $\$ 2,600,000$ \\
Oakland's Estimated Cost per Week & b & $\$ 760,000$ \\
San Francisco Bay Area's Approximate Cost per Week & $\mathrm{c}=\mathrm{a}+\mathrm{b}$ & $\$ 3,360,000$ \\
San Francisco Bay Area's Approximate Cost per Day & $\mathrm{d}=\mathrm{c} / 7$ & $\$ 480,000$ \\
Median Number of Days at Orange & $\mathrm{e}$ & 20 \\
San Francisco Bay Area's Cost for Average Terror Alert & $\mathrm{f}=\mathrm{d}^{*} \mathrm{e}$ & $\$ 9,600,000$ \\
\hline
\end{tabular}

Table A-4: Calculations to Determine Costs of Waiting Time at Airports

\begin{tabular}{llr}
\hline Total Passengers at SFO in 2004 & $\mathrm{a}$ & $32,247,746$ \\
Passengers Departing SFO per Day & $\mathrm{b}=(\mathrm{a} / 2) / 365$ & 44,175 \\
Increased Wait Time per Person (in Hours) & $\mathrm{c}$ & 0.5 \\
Increased Wait Time per Day (in Hours) & $\mathrm{d}=\mathrm{b}^{*} \mathrm{c}$ & 22,087 \\
Average Hourly Rate of Travel Time Saved (2000 Dollars) & $\mathrm{e}$ & $\$ 28.60$ \\
Cost of Additional Travel Time per Day & $\mathrm{f}=\mathrm{d}^{*} \mathrm{e}$ & $\$ 631,702$ \\
Median Number of Days at Orange & $\mathrm{g}$ & 20 \\
San Francisco's Cost for Average Terror Alert (2000 Dollars) & $\mathrm{h}=\mathrm{f}^{*} \mathrm{~g}$ & $\$ 12,634,048$ \\
San Francisco's Cost for Average Terror Alert (2003 Dollars) & $\mathrm{i}=\mathrm{h}^{* 1,068525}$ & $\$ 13,499,797$ \\
\hline
\end{tabular}

Table A-5: Calculations of Estimated Benefits of Preventing a Terrorist Attack in San Francisco or Oakland

\begin{tabular}{llr}
\hline Estimated Cost of $9 / 11$ (2001 Dollats) & $\mathrm{a}$ & $\$ 83,000,000,000$ \\
2001 Population of NYC* & $\mathrm{b}$ & $8,067,993$ \\
$\begin{array}{l}\text { Per Capita Cost of } 9 / 11 \\
2004 \text { Combined Population of San Francisco and Oakland* }\end{array}$ & $\mathrm{c}=\mathrm{a} / \mathrm{b}$ & $\$ 10,288$ \\
$\begin{array}{l}\text { Estimated Benefits of Preventing a Future Attack in San Francisco } \\
\text { or Oakland (2001 Dollars) }\end{array}$ & $\mathrm{e}=\mathrm{c}^{*} \mathrm{~d}$ & $1,142,206$ \\
$\begin{array}{l}\text { Estimated Benefits of Preventing a Future Attack in San Francisco } \\
\text { or Oakland (2003 Dollars) }\end{array}$ & $\mathrm{f}=\mathrm{e}^{*} 1.03896$ & $\$ 11,750,518,128$ \\
\hline
\end{tabular}

*Population Data for NYC, San Francisco and Oakland were obtained from the U.S. Census Bureau. 
Table A-6: Calculations for Estimated Benefits from Crime Reduction

City of San Francisco

Number of Burglaries

a 5,784

Number of Motor Vehicle Thefts

$\mathrm{b}$

6,991

Total Burglaries and Auto Thefts

$c=a+b$

12,775

City of Oakland

Number of Burglaties

d $\quad 4,568$

Number of Motor Vehicle Thefts

e

Total Burglaries and Auto Thefts

$\mathrm{f}=\mathrm{d}+\mathrm{e}$

10,079

Total Burglaries and Auto Thefts

$\mathrm{g}=\mathrm{c}+\mathrm{f}$

22,854

Average Number of Burglaries and Auto Thefts per Day

$\mathrm{h}=\mathrm{g} / 365$

63

Median Number of Days per Orange Alert

i

19.5

Estimated Number of Burglaries and Auto Thefts during Orange Alert

$\mathrm{j}=\mathrm{h} * \mathrm{i}$

1221

Estimated Number of Burglaries and Auto Thefts Prevented

$\mathrm{k}=\mathrm{j}^{*} .075$

Cost Per Burglary (1999 dollars)

1

$\$ 16,200$

Estimated Benefits from Crime Reduction (1999 Dollars)

$\mathrm{m}=\mathrm{k} * 1$

$\$ 1,483,475$

Estimated Benefits from Ctime Reduction (2003 Dollats)

$n=m^{*} 1.104442$

$\$ 1,638,412$

Table A-7: Net Present Value of Raising the Alert

\begin{tabular}{lllr}
\hline & Preventing a Terrorist Attack & $\mathrm{a}$ & $\$ 12,208,330,064$ \\
\multirow{3}{*}{ Benefits } & Probability of Terrorist Attack & $\mathrm{b}$ & 0.0019 \\
& Expected Value of Preventing an Attack & $\mathrm{c}=\mathrm{a} * \mathrm{~b}$ & $\$ 23,195,827$ \\
& Reduction in Crime & $\mathrm{d}$ & $\$ 1,638,412$ \\
& Total Benefits & $\mathrm{e}=\mathrm{c}+\mathrm{d}$ & $\$ 24,834,239$ \\
\hline \multirow{2}{*}{ Costs } & Increased Security Presence & $\mathrm{f}$ & $\$ 9,600,000$ \\
& Increased Waiting at Airports & $\mathrm{g}$ & $\$ 13,499,797$ \\
& Total Costs & $\mathrm{h}=\mathrm{f}+\mathrm{g}$ & $\$ 23,099,797$ \\
\hline
\end{tabular}

Table A-8: Assumptions in Sensitivity Analysis

\begin{tabular}{|c|c|c|c|c|}
\hline & Base Case & Minimums & Maximums & Distributions \\
\hline Waiting Time at Airports & $\$ 13,499,797$ & $\$ 0$ & $\$ 22,406,377$ & Triangular \\
\hline Preventing a Terrorist Attack & $\$ 12,208,330,064$ & $\$ 7,942,768,958$ & $\$ 15,444,272,973$ & Triangular \\
\hline Reduction in Crime & $\$ 1,638,412$ & $\$ 0$ & $\$ 3,276,824$ & Uniform \\
\hline
\end{tabular}


Figure 1: Assumed Probability Distributions for Variables in

\section{Sensitivity Analysis}
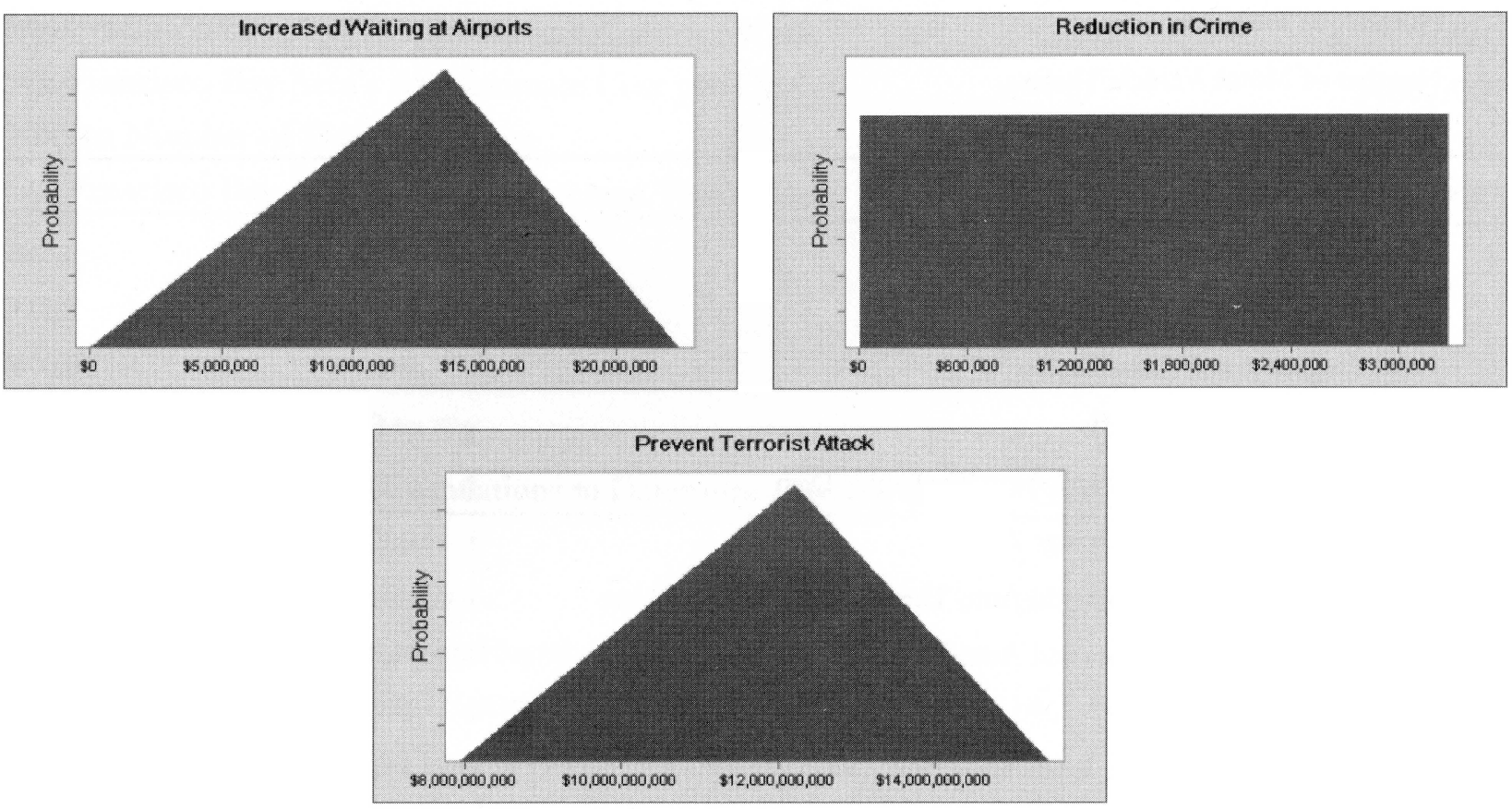

Figure 2: Realized Net Benefits Given the Probability of a Terrorist Attack

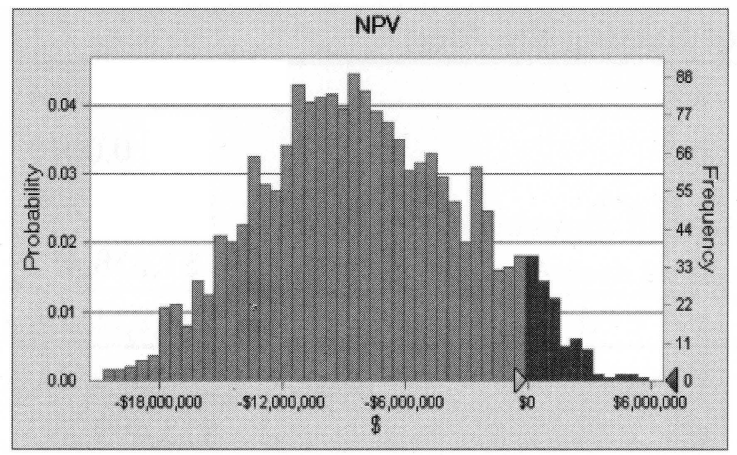

1 in 1000

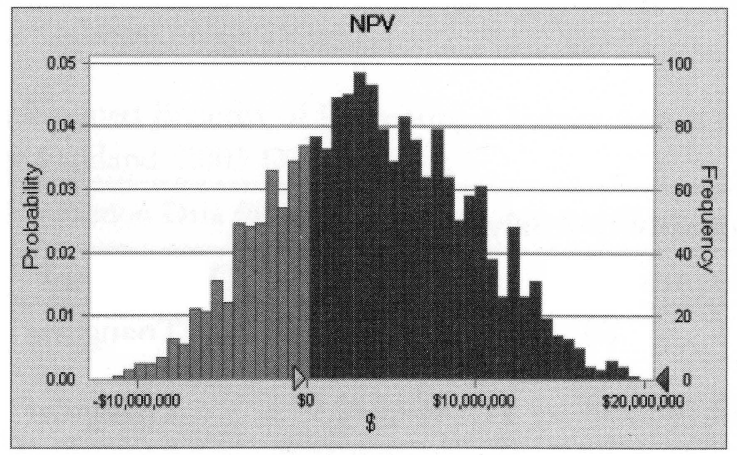

2 in 1000

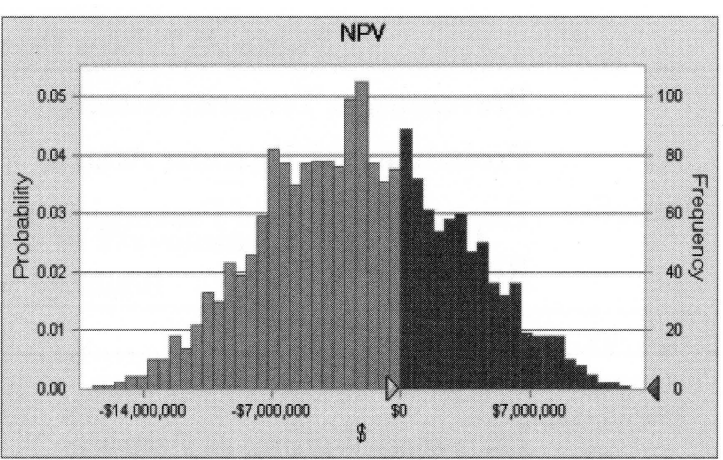

1.5 in 1000

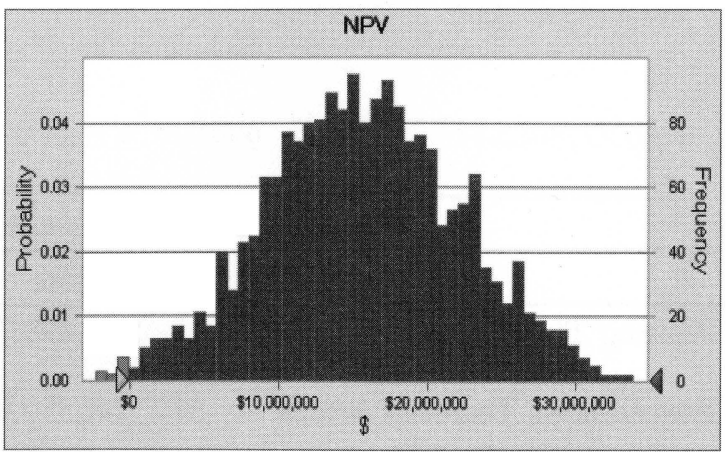

3 in 1000 
Table A-9: Simulated Net Benefits Conditional on Assumed Probabilities

\begin{tabular}{ccc}
\hline Probability Level & Simulated Net Benefits & Chance Simulated Net Benefits are Positive \\
\hline 0.001 & $-\$ 8,065,896$ & $6.06 \%$ \\
0.0015 & $-\$ 2,133,207$ & $34.47 \%$ \\
0.002 & $\$ 3,800,132$ & $73.60 \%$ \\
0.003 & $\$ 15,664,791$ & $99.33 \%$ \\
\hline
\end{tabular}

